\title{
Ultrasonographic Measurement of Transverse Abdominis in Stroke Patients
}

\author{
Hyun Dong Kim, MD, PhD, Jun Myeong You, MD, Nami Han, MD, PhD, \\ Mi Ja Eom, MD, Jong Gil Kim, MD \\ Department of Physical Medicine and Rehabilitation, Inje University Busan Paik Hospital, \\ Inje University College of Medicine, Busan, Korea
}

Objective To compare transverse abdominis (TrA) contractility in stroke patients with hemiparesis and healthy adults using musculoskeletal ultrasonography.

Methods Forty-seven stroke patients with hemiparesis and 25 age-matched healthy control subjects participated in this study. Stroke patients were divided into three groups on the basis of their degree of ambulation. Group A consisted of 9 patients with wheelchair ambulation, group B of 23 patients with assisted ambulation, and group $\mathrm{C}$ of 15 patients with independent ambulation. Inter-rater reliability regarding ultrasonographic measurement of abdominal muscle thickness in the control group was assessed by two examiners. The TrA contraction ratio (TrA contracted thickness/TrA resting thickness) was measured during abdominal drawing-in maneuver and was compared between the patients and the control group and between the ambulation groups.

Results The inter-rater reliability ranged from 0.900 to 0.947 . The TrA contraction ratio was higher in the nonparetic side than in the paretic side $(1.40 \pm 0.62$ vs. $1.14 \pm 0.35, \mathrm{p}<0.01)$. The TrA contraction ratio of the patient group was lower in the non-paretic side as well as in the paretic side than that of the control group (right 1.85 \pm 0.29 , left 1.92 $\pm 0.42 ; \mathrm{p}<0.001$ ). No difference was found between the ambulation regarding the TrA contraction ratio.

Conclusion The TrA contractility in hemiparetic stroke patients is significantly decreased in the non-paretic side as well as in the paretic side compared with that of healthy adults. Ultrasonographic measurement can be clinically used in the evaluation of deep abdominal muscles in stroke patients.

Keywords Ultrasonography, Abdominal muscles, Stroke, Muscle contraction, Paresis

Received August 26, 2013; Accepted October 17, 2013

Corresponding author: Jun Myeong You

Department of Physical Medicine and Rehabilitation, Inje University Busan Paik Hospital, Inje University College of Medicine, 75 Bokji-ro, Busanjin-gu, Busan 614-735, Korea

Tel: +82-51-890-6114, Fax: +82-51-891-1430, E-mail: amaro-te@hanmail. net

(c) This is an open-access article distributed under the terms of the Creative Commons Attribution Non-Commercial License (http://creativecommons. org/licenses/by-nc/3.0) which permits unrestricted noncommercial use, distribution, and reproduction in any medium, provided the original work is properly cited.

Copyright $\odot 2014$ by Korean Academy of Rehabilitation Medicine

\section{INTRODUCTION}

Abdominal muscles are known to play an important role in the performance of functional movements and in the stabilization of the trunk, not only in a static state but also in a dynamic state where movements, such as upper limb flexion and extension, can affect the body balance. A lot of research has been carried out on trunk muscle strength and trunk balance in patients with low back pain and in healthy populations using isokinetic machines, 
electromyography (EMG), functional tests, and musculoskeletal ultrasound.

The importance of the transverse abdominis (TrA) has been emphasized in studies on the trunk stabilizing muscles or the core muscles. Hodges et al. [1] demonstrated its involvement in unloading of the spine, anticipatory postural control [2] and intersegmental stabilization of the spine [3]. The research on patients with low back pain using ultrasonography revealed a decreased activity of TrA in patients with low back pain compared to the unaffected side of the patients and to healthy subjects [4-7].

Trunk muscle strength and trunk stability have been investigated in patients with stroke using an isokinetic machine, EMG, and functional tests.

Previous research demonstrated that the peak torque of the trunk flexion and extension measured by an isokinetic dynamomter was significantly smaller in hemiplegic patients than in healthy controls, although the trunk muscle weakness was not detected in the physical examinations of those patients [8]. There was a significant positive correlation between trunk flexion and extension muscle strength and the Berg Balance Scale score at discharge and locomotion transfers. The Functional Independence Measure (FIM) subscore at discharge was positively correlated with trunk flexion muscle torque values [9]. Dickstein et al. [10] reported major impairments in the activity of the trunk muscles and also a reduced activity of the lateral trunk muscles, delayed onset of the muscles and reduced synchronization between the activation of pertinent muscles pairs in hemiparetic subjects. Those problems were associated with motor and functional deficits [10]. Other research showed that stroke patients with balance problems take longer to reach the same functional gains as those without balance problems [11] and that trunk control at an early stage after stroke has a strong predictive value for comprehensive activities of daily living (ADL) functions 6 months after a stroke [12].

The standing balance has shown to have a significant correlation with ADL functions measured by FIM scores [13], and sitting balance was found to have a strong positive correlation with ADL functions measured by the Barthel index [14].

As described above, there is a close relationship between the trunk muscles of stroke patients and their overall functioning, balance and prognosis. Most studies have used isokinetic machines, EMG, and ultrasonography as tools to evaluate the abdominal muscles in patients with stroke. There are a limited number of studies on TrA in stroke patients. Moreover, studies that have been conducted on stroke patients lack comparisons with control groups $[15,16]$. Previous studies also involved patients who had suffered a stroke more than 6 months earlier. Further studies are needed focusing on the effects of rehabilitative treatment in subacute stroke patients and chronic patients.

Rehabilitative ultrasound imaging is a noninvasive method to visualize the lateral abdominal wall and qualitatively and quantitatively assess deep muscular activity during exercise. The change of muscle thickness during the abdominal drawing-in maneuver (ADIM) has been validated with EMG studies $[17,18]$. However, that the transducer can inevitably cause inter-rater or intra-rater reliability problems is a disadvantage of ultrasonography scans of the body including abdominal muscles. Although the usefulness of ultrasonography in the measurement of muscle thickness has been verified in many studies, not all anatomical site evaluations have been shown to be reliable. In acute stroke patients, only four sites (anterior upper arm, posterior upper arm, abdomen and anterior thigh) were considered to provide reliable measures of muscle thickness [19].

The aim of the present study was to exploit the advantages of ultrasonography in the investigation of TrA activity in patients with stroke. So, the purposes of this study were 1) to determine the inter-rater reliability of measuring abdominal muscle thickness using ultrasonography, 2) to compare the activation of the TrA between healthy controls and stroke patients and between affected and unaffected sides in stroke patients, and 3) to determine whether there is a difference in the activation of the TrA between groups with diverse ambulatory levels.

\section{MATERIALS AND METHODS}

\section{Subjects}

Between February 2011 and March 2013, stroke patients were included in the study who were admitted for a comprehensive rehabilitation or visited the out-patient clinic of the Department of Physical and Rehabilitation Medicine at Inje University Busan Paik Hospital, Busan, Republic of Korea.

The inclusion criteria were as follows: patients having a 
Table 1. General characteristics of subjects

\begin{tabular}{lcccc}
\hline \multicolumn{1}{c}{ Characteristic } & $\begin{array}{c}\text { Normal control } \\
(\mathbf{n = 2 5})\end{array}$ & $\begin{array}{c}\text { Group A } \\
(\mathbf{n = 9 )}\end{array}$ & $\begin{array}{c}\text { Group B } \\
(\mathbf{n}=\mathbf{2 3})\end{array}$ & $\begin{array}{c}\text { Group C } \\
(\mathbf{n}=\mathbf{1 5})\end{array}$ \\
\cline { 3 - 5 } & $49.48 \pm 9.52$ & $52.22 \pm 7.98$ & $51.96 \pm 8.63$ & $50.79 \pm 11.37$ \\
\hline Age (yr) & $13: 12$ & $5: 4$ & $15: 8$ & $7: 5$ \\
\hline Sex (male:female) & - & $7: 2$ & $20: 3$ & $13: 2$ \\
\hline Diagnosis (ischemic:hemorrhagic) & - & $71.44 \pm 22.08$ & $87.43 \pm 30.62$ & $73.67 \pm 34.28$ \\
Duration (day) & - & $4: 5$ & $12: 11$ & $10: 5$ \\
Affected side (right:left) & 15 & $3.56 \pm 1.13$ & $6.04 \pm 2.49$ & $12.40 \pm 1.05$ \\
\hline K-MBI (ambulation or wheelchair) & $29.32 \pm 0.96$ & $27.11 \pm 1.26$ & $27.48 \pm 1.67$ & $28.07 \pm 1.43$ \\
\hline K-MMSE & $23.06 \pm 1.40$ & $23.17 \pm 1.23$ & $22.45 \pm 1.64$ & $22.90 \pm 1.55$ \\
\hline BMI $\left(\mathrm{kg} / \mathrm{m}^{2}\right)$ & & & & \\
\hline
\end{tabular}

Values are presented as mean \pm standard deviation.

K-MBI, Korean Modified Barthel Index; K-MMSE, Korean Mini-Mental Status Examination; BMI, body mass index.

unilateral hemispheric lesion confirmed by neurological examinations and computed tomography or magnetic resonance imaging (MRI); patients 1 to 5 months poststroke; patients with hemiparesis (or plegia) following a first stroke; patients without cognitive deficits (Mini Mental State Examination [MMSE] at least 25); patients who were able to understand and follow verbal instructions; patients without a history of lumbar operations; patients without a history of abdominal operations; medically stable patients; and patients who could sign an informed consent or could have authorized representatives sign the informed consent. Exclusion criteria were as follows: patients with low back pain; patients with a history of lumbar operations; patients with a history of abdominal operations; patients with a history of previous brain lesions; patients with a neurological disorder other than stroke; and obese patients (body mass index [BMI] at least 25). The control group was comprised of a healthy population who met the inclusion and exclusion criteria, excluding the items related to stroke and hemiparesis.

Forty-seven hemiparetic stroke patients and 25 agematched healthy control subjects participated in the current study. Twenty-six patients were right hemiparetic and 21 were left hemiparetic. The stroke patients were divided into three groups on the basis of their degree of ambulation, which was measured by the items of the Modified Barthel Index (MBI). The wheelchair ambulation group (group $\mathrm{A}, \mathrm{n}=9$ ) was defined as patients with a score of 1 to 5 in the wheelchair ambulation item. The assisted ambulation group (group $B, n=23$ ) had a score of 2 to 3 in the ambulation item and the independent ambu-

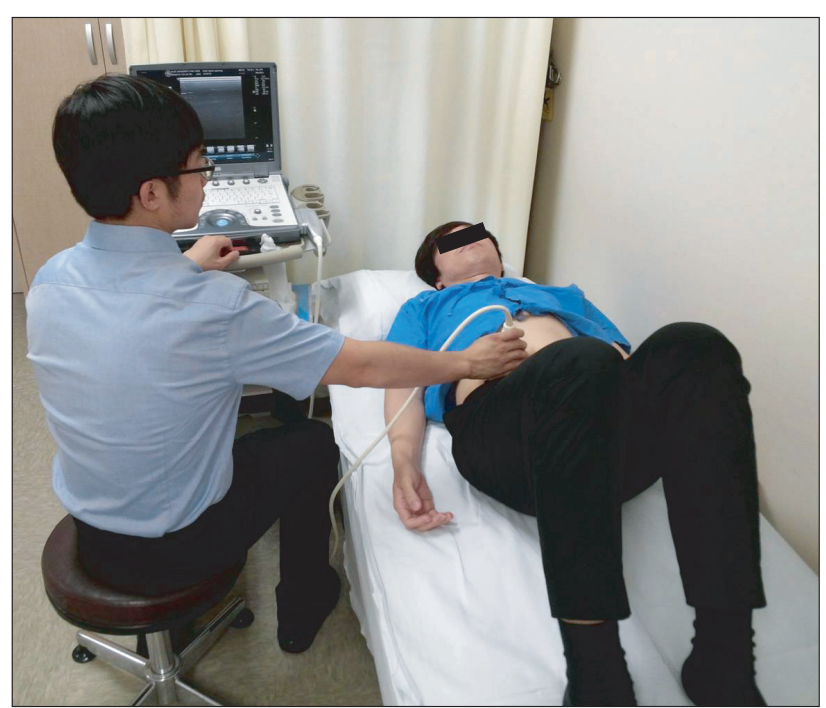

Fig. 1. Positioning of subjects during abdominal muscle measurement using ultrasonography.

lation group (group $C, n=15$ ) had a score of 4 to 5 in the ambulation item (Table 1).

\section{Methods}

The participants were instructed how to perform the ADIM. The following instruction preceded the contraction: "Breathe in, breathe out, do not breathe in and gently and slowly draw your lower abdomen in toward the spine." The ADIM contraction was held for 5-10 seconds. During the instructions, ultrasonography was used to determine whether the TrA was selectively activated while the superficial abdominal muscles were relaxed. The ultrasound recordings during the ADIM were performed 
with the subject in a supine hook-lying position and with the examiner sitting to the right side of the subject [20] (Fig. 1).

The ultrasound images of the TrA were obtained using a LOGIQ e (GE Healthcare, Milwaukee, WI, USA) with a $12 \mathrm{MHz}$ linear transducer. The images were recorded in $B$ mode. The transducer was placed on either side of the umbilicus in a transverse plane along the mid-axillary line. The hyperechoic interface between the TrA and the thoracolumbar fascia was set to be the right most structure of the ultrasound image to standardize the placement of the transducer among the subjects. The angle of the transducer was altered to ensure that the best image was captured and that the fascial layers of the abdominal muscles were parallel on the screen.

After capturing the image, the thickness of the $\operatorname{TrA}$, the external oblique (EO) and internal oblique (IO) were measured using the distance between the superior edge of the deep hyperechoic fascial line to the inferior edge of the superior fascial line [4] (Fig. 2).

The TrA contraction ratio was calculated by dividing the muscle thickness at the maximal contraction by the muscle thickness at rest. The contraction ratio of the $\mathrm{EO}+\mathrm{IO}$ was calculated in the same manner to determine whether the muscle thickness of the EO and IO remained relatively constant and to assess whether the ADIM was performed in the correct manner [21]. The thickness measurements were saved in Microsoft Excel, and the TrA and EO+IO contraction ratios were calculated.

The abdominal muscle thickness of 25 control subjects was measured by two experienced examiners to evaluate the inter-rater reliability in the measurement of the abdominal muscles. The subjects were kept in the supine hook-lying position. Sitting to the right side of the sub- ject, the first examiner measured the abdominal muscle thickness with the transducer placed on either side of the umbilicus in a transverse plane along the mid-axillary line. Then the second examiner measured the abdominal muscle thickness of the subjects in the same manner two or three days later.

\section{Statistical analysis}

Descriptive statistics were used to compare the demographic and clinical characteristics of the patient and the control groups. Reliability measures were determined for the TrA, EO and IO in a relaxed state using the intraclass correlation coefficient (ICC). A paired t-test was used to compare the TrA contraction ratio between the body sides, and an independent t-test was employed to compare the TrA contraction ratio between the patient and the control groups. A one-way analysis of variance (ANOVA) was conducted for comparisons of the TrA contraction ratio within the patient subgroup (group A-C). A $p$-value of $<0.05$ was considered to indicate statistical significance. All the data were analyzed using SPSS ver. 17.0 for Windows (SPSS Inc., Chicago, IL, USA).

\section{RESULTS}

\section{Demographic characteristics}

The characteristics of the patients were as follows. The average age of the subjects was 50.78 years, ranging from 29 to 66 years. The average time from stroke onset to ultrasonographic evaluation was 101.38 days, ranging from 32 to 170 days. The average K-MBI subscore was 7.59 points, ranging from 1 to 15 points. The average K-MMSE score was 27.48 points, ranging from 25 to 30 points. The average BMI was $22.48 \mathrm{~kg} / \mathrm{m}^{2}$, ranging from 19.1 to 24.9
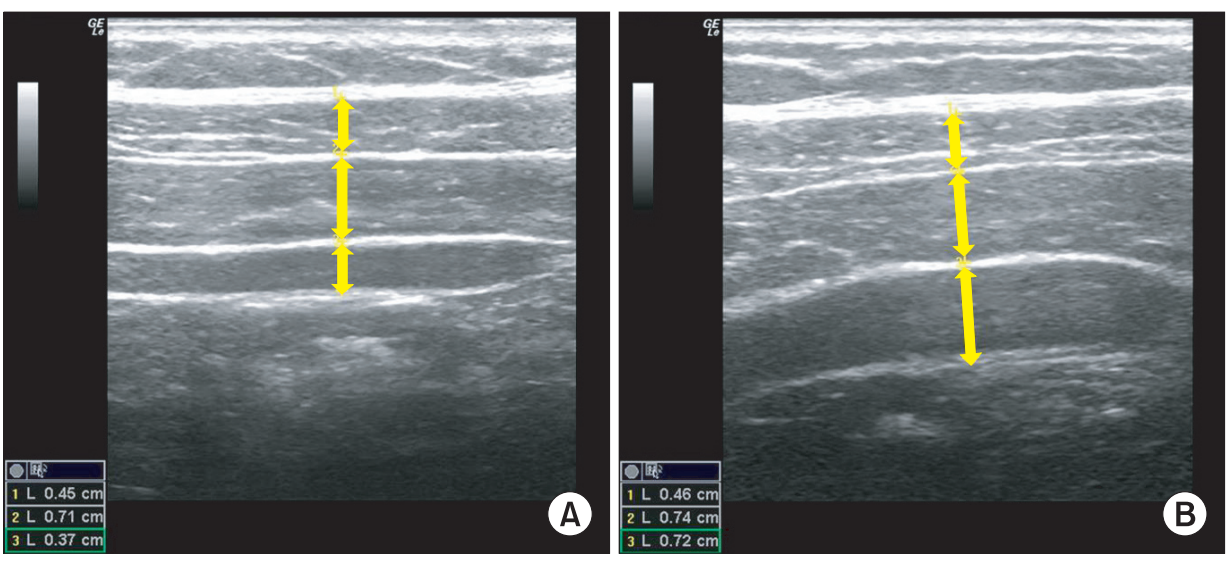

Fig. 2. Lateral abdominal muscles at rest (A) and during abdominal drawing-in maneuver (B). 
$\mathrm{kg} / \mathrm{m}^{2}$. Except for the K-MBI subscore $(\mathrm{p}<0.01)$, there were no significant differences between the groups classified by the degree of ambulation in age, illness duration, K-MMSE score, and BMI ( $\mathrm{p}>0.05)$.

The characteristics of the control group were as follows. The average age of the subjects was 49.48 years, ranging from 29 to 67 years. The average K-MBI subscore was 15 points, with all participants obtaining 15 points. The average K-MMSE score was 29.32 points, ranging from 27 to 30 points. The average BMI was $23.06 \mathrm{~kg} / \mathrm{m}^{2}$, ranging from 19.5 to $24.8 \mathrm{~kg} / \mathrm{m}^{2}$.

Except for the K-MBI subscore ( $p>0.05)$, there were no significant differences between the patient and control groups in age, K-MMSE score or BMI $(\mathrm{p}<0.01)$.

\section{Inter-rater reliability analysis}

The ICC scores for inter-rater reliability ranged from 0.900 (left IO) to 0.947 (left TrA) and the confidence interval was within an acceptable range of 0.70 to 1.00 (Table 2).

\section{Muscle thickness during the resting state}

There were no significant differences between the right

Table 2. Inter-rater reliability

\begin{tabular}{lcccc}
\hline \multirow{2}{*}{ Muscle } & \multirow{2}{*}{ ICC } & \multicolumn{2}{c}{ 95\% CI } & \multirow{2}{*}{ p-value } \\
\cline { 3 - 4 } & & Upper & Lower & \\
\hline Rt. EO & 0.928 & 0.968 & 0.844 & $<0.001$ \\
Rt. IO & 0.935 & 0.971 & 0.859 & $<0.001$ \\
Rt. TrA & 0.936 & 0.971 & 0.860 & $<0.001$ \\
\hline Lt. EO & 0.924 & 0.966 & 0.834 & $<0.001$ \\
\hline Lt. IO & 0.900 & 0.955 & 0.786 & $<0.001$ \\
\hline Lt. TrA & 0.947 & 0.976 & 0.885 & $<0.001$ \\
\hline
\end{tabular}

ICC, intraclass correlation coefficient; CI, confidence interval; Rt., right; Lt., left; EO, external oblique abdominis; IO, internal oblique abdominis; TrA, transverse abdominis. and left sides of the abdomen with respect to muscle thickness of the TrA, EO or IO during the resting state in the control group $(\mathrm{p}=0.85, \mathrm{p}=0.78$, and $\mathrm{p}=0.56$, respectively) (Table 3).

There were no significant differences between the paretic and non-paretic sides of the abdomen with respect to the muscle thickness of the TrA, EO or IO during the resting state in the patient group $(\mathrm{p}=0.22, \mathrm{p}=0.98$, and $\mathrm{p}=0.90$, respectively) (Table 3 ).

In the comparison between the patient and the control groups, the resting thickness of the TrA, EO, and IO of the patients was lower than that of the healthy controls and these differences were statistically significant $(\mathrm{p}<0.05)$.

\section{Contraction ratio}

There were no statistically significant differences between both sides of the abdomen regarding the TrA, $\mathrm{EO}, \mathrm{IO}$ and $\mathrm{EO}+\mathrm{IO}$ contraction ratio in the control group ( $\mathrm{p}=0.39, \mathrm{p}=0.63, \mathrm{p}=0.91$, and $\mathrm{p}=0.52$, respectively) (Table 4).

There were no significant differences between the paretic and non-paretic sides of the abdomen with respect to the EO, IO, and EO+IO contraction ratio in the patient group ( $\mathrm{p}=0.11, \mathrm{p}=0.96$, and $\mathrm{p}=0.26$, respectively) (Table 5). However, the TrA contraction ratio of the paretic side

Table 4. Contraction ratio in control group

\begin{tabular}{lcc}
\hline \multirow{2}{*}{ Muscle } & \multicolumn{2}{c}{ Contraction ratio } \\
\cline { 2 - 3 } & Right & Left \\
\hline EO & $0.93 \pm 0.18$ & $0.90 \pm 0.20$ \\
IO & $1.06 \pm 0.30$ & $1.09 \pm 0.26$ \\
EO+IO & $0.98 \pm 0.14$ & $0.98 \pm 0.15$ \\
TrA & $1.85 \pm 0.29$ & $1.92 \pm 0.42$ \\
\hline
\end{tabular}

Values are presented as mean \pm standard deviation.

EO, external oblique abdominis; IO, internal oblique abdominis; TrA, transverse abdominis.

Table 3. Resting thickness of abdominal muscles in the control and patient group (unit, $\mathrm{cm}$ )

\begin{tabular}{lccccc}
\hline \multirow{2}{*}{ Muscle } & \multicolumn{2}{c}{ Control group } & & \multicolumn{2}{c}{ Patient group } \\
\cline { 2 - 3 } \cline { 5 - 6 } \cline { 5 - 6 } & Right & Left & & Non-paretic & Paretic \\
\hline EO & $0.83 \pm 0.20$ & $0.82 \pm 0.17$ & & $0.57 \pm 0.14$ & $0.60 \pm 0.18$ \\
TrA & $0.86 \pm 0.22$ & $0.87 \pm 0.23$ & & $0.65 \pm 0.20$ & $0.65 \pm 0.18$ \\
\hline
\end{tabular}

Values are presented as mean \pm standard deviation.

EO, external oblique abdominis; IO, internal oblique abdominis; TrA, transverse abdominis. 
Table 5. Contraction ratio in the patient group

\begin{tabular}{|c|c|c|c|c|}
\hline \multirow{2}{*}{ Muscle } & \multicolumn{4}{|c|}{ Contraction ratio } \\
\hline & Group A & Group B & Group C & Overall \\
\hline \multicolumn{5}{|c|}{ Non-paretic } \\
\hline EO & $0.94 \pm 0.13$ & $0.91 \pm 0.13$ & $0.88 \pm 0.21$ & $0.91 \pm 0.16$ \\
\hline IO & $1.05 \pm 0.21$ & $1.05 \pm 0.13$ & $1.16 \pm 0.19$ & $1.08 \pm 0.17$ \\
\hline $\mathrm{EO}+\mathrm{IO}$ & $0.99 \pm 0.10$ & $1.00 \pm 0.11$ & $1.01 \pm 0.09$ & $1.00 \pm 0.10$ \\
\hline $\operatorname{TrA}$ & $1.31 \pm 0.19$ & $1.47 \pm 0.79$ & $1.35 \pm 0.50$ & $1.40 \pm 0.62^{\mathrm{a}, \mathrm{b})}$ \\
\hline \multicolumn{5}{|l|}{ Paretic } \\
\hline $\mathrm{EO}$ & $0.85 \pm 0.08$ & $0.87 \pm 0.13$ & $0.87 \pm 0.20$ & $0.86 \pm 0.15$ \\
\hline IO & $1.03 \pm 0.24$ & $1.05 \pm 0.25$ & $1.18 \pm 0.30$ & $1.09 \pm 0.27$ \\
\hline $\mathrm{EO}+\mathrm{IO}$ & $0.99 \pm 0.10$ & $0.99 \pm 0.16$ & $0.94 \pm 0.15$ & $0.98 \pm 0.15$ \\
\hline $\operatorname{TrA}$ & $1.14 \pm 0.28$ & $1.11 \pm 0.39$ & $1.20 \pm 0.32$ & $1.14 \pm 0.35^{\mathrm{b})}$ \\
\hline
\end{tabular}

Values are presented as mean \pm standard deviation.

EO, external oblique abdominis; IO, internal oblique abdominis; TrA, transverse abdominis.

${ }^{a} \mathrm{p}<0.01$ corresponding value in paretic side. ${ }^{\text {b) }} \mathrm{p}<0.001$ corresponding value in control group.

was significantly lower than that of the non-paretic side $(\mathrm{p}<0.01)$.

There were no significant differences with respect to the TrA, EO, IO, and EO+IO contraction ratio between the groups classified by the degree of ambulation. In the comparison between the patient and the control groups, the TrA contraction ratio of the paretic side was significantly lower than that of the control group $(\mathrm{p}<0.001)$ and the TrA ratio of the non-paretic side was lower than that of the control group, which was statistically significant $(\mathrm{p}<0.001)$.

\section{DISCUSSION}

The ICC value for the abdominal muscles was not less than 0.900 in any of the groups and the inter-rater reliability for the abdominal muscle thickness measurements using ultrasonography could be considered within the acceptable range. The reliability of ultrasonography in the current study was consistent with that of previous studies in healthy subjects or patients with low back pain $[19,21,22]$. Compared with a previous study on acute stroke patients, the reliability indices in the present study were high [19]. Research on ultrasonographic measurement of the abdominal muscles has utilized several structures as a landmark of the exam, such as the point just superior to the iliac crest $[4,22]$, the point halfway between the first costal cartilage, the iliac crest [22], and the umbilicus [19]. In the current study, the reliability evalu- ation was performed on healthy adults and the umbilicus was used as a landmark because it is relatively convenient to locate. The use of this landmark might have caused the reliability indices to be high.

The position of the umbilicus is influenced by the amount of subcutaneous fat tissue. Thus, ultrasonographic measurements of abdominal muscles may have limitations in several populations, such as in obese subjects and patients who have undergone abdominal operations. These factors probably have a limited influence on the present study, as we excluded subjects with a history of abdominal operations and obese subjects from participation. As reported in a previous study, the reliability of ultrasonographic measurements of abdominal muscles is influenced by the operator's level of training. This likely explains the high level of inter-rater reliability in the current study [22].

ADIM has been described as the best way to activate the TrA [23-26]. The ADIM is an inward movement of the lower abdominal wall in which the patient is instructed to draw the umbilicus toward the spine. A key feature is to teach the patient to preferentially activate the TrA while maintaining relaxation of the more superficial musculature [4].

EO+IO contraction ratios were obtained to determine whether ADIM was performed appropriately and the values of the EO+IO contraction ratios in the patient and the control groups were close to 1.0. It means that the EO and IO were not contracting significantly. This finding is 
similar to that reported in previous research [21]. Based on the findings in the present study, the ADIM was considered to have been performed properly.

There were no significant differences in the EO+IO contraction ratio between the patient and the control groups or between the groups classified by the degree of ambulation. Thus, there don't seem to have been any significant differences between the subjects in the ADIM performance. Although the patient group was classified by the degree of ambulation, this group probably had no problem in understanding and performing the ADIM because they had appropriate cognitive functioning.

The TrA contraction ratio has been developed to examine the recruitment of the TrA during an active contraction [27]. Musculoskeletal ultrasonography is a noninvasive method to visualize the lateral abdominal wall and quantitatively and qualitatively assess deep muscular activity with exercise. The change in muscle thickness during the ADIM has been validated with EMG studies and is an indicator of muscle activation $[17,18]$.

In the control group, the values of the TrA contraction ratio were comparable to those of previous studies, and the side-to-side differences were not statistically significant [4]. The TrA contraction ratio was less than 2.0 on average. However, a previous study reported values ranging from 2.22 to 2.43 [21]. That study was conducted with active duty soldiers with nonspecific low back pain and the average age of the subjects was younger than that of the current study. These factors might have contributed to the higher values.

In the patient group, the TrA contraction ratio of the paretic side was significantly lower than that of the nonparetic side. Some EMG-related research has reported delayed or reduced activity of the lateral trunk muscles and reduced synchronization between the activation of pertinent muscular pairs in stroke patients. However, we were unable to find any studies regarding $\operatorname{TrA}$ activation in stroke patients $[10,28,29]$.

In previous studies of bilateral innervation of the trunk muscles, the activity of the unilateral trunk was impaired. However, the exact mechanism of the unilateral impairment remains still unclear [10]. Predominant bilateral innervation of the axial muscles, such as the rectus abdominis and to a lesser extent, the lateral trunk muscles likely explain these impairment. It is possible that unilateral brain lesions have a greater influence on the lateral trunk muscles, such as the TrA, than on other muscles, thus explaining the low values of the TrA contraction ratio in the present study [30-32].

Noteworthy findings in the present study are the differences in the TrA contraction ratio between the paretic and non-paretic sides during low-intensity exercise, such as ADIM. In research conducted on patients with low back pain, the TrA contraction ratio of the painful side was lower than that of the non-painful side. However, these results were found during mid-to-high intensity exercises, such as bridge exercise or sling bridge exercise [4]. The ceiling effect or other factors are considered to inhibit low-intensity exercise, such as ADIM, and produce differences in low back pain patients [21]. Mid-to-high intensity core exercise could not be performed in the current study because of the characteristics of the stroke patients. Thus, we did not expect to detect significant differences in the TrA contraction ratio between the paretic and non-paretic sides. It is more likely that factors related to muscle atrophy had a negative effect on the TrA contractility in the patient group considering that there were no significant differences in the TrA thickness between the paretic and non-paretic sides during the resting state, that the ADIM was performed appropriately and that there were significant differences in the TrA thickness between the patient and the control groups during the resting state. These factors may explain the significant TrA contractility differences between the affected and unaffected side during the low-intensity ADIM exercise.

In common with the results of previous studies in healthy adults and low back pain patients, there were TrA contraction ratio differences between the paretic and non-paretic sides in the present study. In addition, the TrA contraction ratio of the paretic side was lower than that of the control group. Two factors may explain these results. First, as previous research demonstrated, the unilateral brain innervates both sides of the trunk muscles. Therefore, unilateral stroke lesions could have a negative effect on the contractility of bilateral trunk muscles and this may be manifested as a decreased TrA contraction ratio. Second, based on the findings that the resting $\operatorname{Tr} A$ thickness of the patient group was lower than that of the control group, as mentioned above, disuse atrophy could be a possible cause of the low TrA contraction ratio in the patients. As the present research was conducted with sub-acute stroke patients, there is a possibility that the 
patients had spent a long time in a bedridden state, followed by trunk muscle atrophy. This may have reduced the muscle mass and contractile properties at the time of the investigation. The disuse atrophy of the patient group may have been manifested as a lower level of TrA contraction ratio compared to that of the control group.

In the patient groups classified by the degree of ambulation, there were no significant differences in the $\operatorname{TrA}$ contraction ratio. Differences between the groups were expected because it was likely that there were discrepancies in the degree of trunk muscle recruitment, trunk balance and disuse atrophy according to the ambulatory level. However, we found no such differences. This may be because various factors determine the ambulation level, such as the muscle strength of the lower limbs and trunk, balance maintenance ability and visual acuity. A functional exam measuring trunk muscle strength and trunk balance is necessary to determine the contribution of these factors and to characterize their association with the TrA contraction ratio.

Ultrasonography is widely utilized in diverse clinical fields and in the evaluation of the musculoskeletal system. Ultrasound imaging is a reliable and valid technique to measure changes in muscle thickness. It has been compared to MRI, which is considered the gold standard for the measurement of muscle geometry [33] and it has been compared to EMG as a standard technique for the monitoring of muscle activation $[17,18]$. Further, ultrasonography has been used to evaluate muscle wasting, the level of physical activity and the response to exercise in acutely ill patients in intensive care settings as well as in healthy populations [19]. The advantages of ultrasonography in clinical settings include no radiation exposure, noninvasiveness, relative low cost, portability and realtime examination. It is common for stroke patients to have multiple comorbid diseases and this occasionally prevents stroke patients undergoing invasive, time-consuming and contrast-using studies. Therefore, characteristics of ultrasonography may have advantages in the evaluation and follow-up of stroke patients.

Research has been conducted on the trunk muscles of stroke patients. Carr et al. [31] demonstrated in their report that unilateral abdominal muscles are innervated from the bilateral sides of the brain. They hypothesized that trunk muscles, including those of the thoracic and abdominal region, would not be affected by unilateral stroke lesions [31,34]. Other studies have demonstrated that trunk function, is decreased in stroke patients in addition to trunk muscle strength $[8,10,13,35,36]$. The results of the current study correspond well with those of earlier work. To our knowledge, the present study is the first to investigate the morphological and functional characteristics of abdominal muscles using ultrasonography in stroke patients.

The present study has several limitations. First, although the TrA activation ratio seems to be a consistent and representative measure of TrA contractility, normative data for TrA activation ratio are lacking. Therefore, the results of the current study were interpreted by comparing the TrA contraction ratio with that of previous research. The interpretation of the results of stroke patients has many restrictions because little research has been conducted on the TrA contraction ratio in patients with stroke. Second, although there were statistically significant findings, a generalization of the study results is impossible due to its small sample size, in particular that of the control group and the subgroups of patients. The third limitation results from the performance difficulties in the ADIM. The ADIM does not require an overload or effortful abdominal contraction, but it requires selective contraction of the TrA. Some patients could not perform the ADIM in an accurate manner after the first instruction. They appropriately performed the ADIM when ultrasonographic guidance was used to give them feedback on whether the TrA was selectively activated while the superficial abdominal muscles were relaxed. However, in some cases, the total number of ADIM repetitions was more than five and this could have caused abdominal muscle fatigue. Finally, functional evaluations, including evaluation of trunk balance and trunk strength, were not conducted. In the future, additional studies should be conducted with a large number of subjects aimed at comprehensively analyzing the activation of the $\operatorname{TrA}$ and the functional characteristics of the trunk in stroke patients.

In the present study, ultrasonographic evaluations were conducted on the activation of the TrA in subacute stroke patients. There was no difference between the groups classified by the level of ambulation. However, the TrA contraction ratio of the paretic side was significantly lower than that of the non-paretic side and the TrA ratio of the non-paretic side was lower than that of the control 
group. The results of this study suggest that ultrasonographic measurements can be clinically used in the deep abdominal muscle evaluation of stroke patients.

\section{CONFLICT OF INTEREST}

No potential conflict of interest relevant to this article was reported.

\section{REFERENCES}

1. Hodges PW, Cresswell AG, Daggfeldt K, Thorstensson $A$. In vivo measurement of the effect of intraabdominal pressure on the human spine. J Biomech 2001;34:347-53.

2. Hodges PW, Richardson CA. Feedforward contraction of transversus abdominis is not influenced by the direction of arm movement. Exp Brain Res 1997;114:362-70.

3. Hodges P, Kaigle Holm A, Holm S, Ekstrom L, Cresswell A, Hansson $\mathrm{T}$, et al. Intervertebral stiffness of the spine is increased by evoked contraction of transversus abdominis and the diaphragm: in vivo porcine studies. Spine (Phila Pa 1976) 2003;28:2594-601.

4. Saliba SA, Croy T, Guthrie R, Grooms D, Weltman A, Grindstaff TL. Differences in transverse abdominis activation with stable and unstable bridging exercises in individuals with low back pain. N Am J Sports Phys Ther 2010;5:63-73.

5. Critchley DJ, Coutts FJ. Abdominal muscle function in chronic low back pain patients: measurement with real-time ultrasound scanning. Physiotherapy 2002;88:322-32.

6. Ferreira PH, Ferreira ML, Hodges PW. Changes in recruitment of the abdominal muscles in people with low back pain: ultrasound measurement of muscle activity. Spine (Phila Pa 1976) 2004;29:2560-6.

7. Ferreira PH, Ferreira ML, Maher CG, Refshauge K, Herbert RD, Hodges PW. Changes in recruitment of transversus abdominis correlate with disability in people with chronic low back pain. Br J Sports Med 2010;44:1166-72.

8. Tanaka S, Hachisuka K, Ogata H. Muscle strength of trunk flexion-extension in post-stroke hemiplegic patients. Am J Phys Med Rehabil 1998;77:288-90.

9. Karatas M, Cetin N, Bayramoglu M, Dilek A. Trunk muscle strength in relation to balance and functional disability in unihemispheric stroke patients. Am J Phys Med Rehabil 2004;83:81-7.

10. Dickstein R, Shefi S, Marcovitz E, Villa Y. Anticipatory postural adjustment in selected trunk muscles in post stroke hemiparetic patients. Arch Phys Med Rehabil 2004;85:261-7.

11. Juneja G, Czyrny JJ, Linn RT. Admission balance and outcomes of patients admitted for acute inpatient rehabilitation. Am J Phys Med Rehabil 1998;77:388-93.

12. Hsieh CL, Sheu CF, Hsueh IP, Wang CH. Trunk control as an early predictor of comprehensive activities of daily living function in stroke patients. Stroke 2002;33:2626-30.

13. Bohannon RW, Leary KM. Standing balance and function over the course of acute rehabilitation. Arch Phys Med Rehabil 1995;76:994-6.

14. Sandin KJ, Smith BS. The measure of balance in sitting in stroke rehabilitation prognosis. Stroke 1990;21:826.

15. Lee YJ, Lee GW, Yi CH, Cynn HS. Comparison of abdominal muscle thickness between the nonparetic and paretic side during quiet breathing in patients with chronic. PTK 2011;18:8-15.

16. Park HJ, Oh DW, Shin WS. The study of asymmetrical contraction of the lateral abdominal muscles in stroke patients using ultrasound imaging. J Korean Soc Phys Med 2012;7:319-27.

17. Hodges PW, Pengel LH, Herbert RD, Gandevia SC. Measurement of muscle contraction with ultrasound imaging. Muscle Nerve 2003;27:682-92.

18. McMeeken JM, Beith ID, Newham DJ, Milligan P, Critchley DJ. The relationship between EMG and change in thickness of transversus abdominis. Clin Biomech (Bristol, Avon) 2004;19:337-42.

19. English CK, Thoirs KA, Fisher L, McLennan H, Bernhardt J. Ultrasound is a reliable measure of muscle thickness in acute stroke patients, for some, but not all anatomical sites: a study of the intra-rater reliability of muscle thickness measures in acute stroke patients. Ultrasound Med Biol 2012;38:368-76.

20. Vasseljen O, Fladmark AM. Abdominal muscle contraction thickness and function after specific and general exercises: a randomized controlled trial in chronic low back pain patients. Man Ther 2010;15:482-9.

21. Teyhen DS, Miltenberger CE, Deiters HM, Del Toro 
YM, Pulliam JN, Childs JD, et al. The use of ultrasound imaging of the abdominal drawing-in maneuver in subjects with low back pain. J Orthop Sports Phys Ther 2005;35:346-55.

22. Ferreira PH, Ferreira ML, Nascimento DP, Pinto RZ, Franco MR, Hodges PW. Discriminative and reliability analyses of ultrasound measurement of abdominal muscles recruitment. Man Ther 2011;16:463-9.

23. Goldman JM, Lehr RP, Millar AB, Silver JR. An electromyographic study of the abdominal muscles during postural and respiratory manoeuvres. J Neurol Neurosurg Psychiatry 1987;50:866-9.

24. Urquhart DM, Hodges PW, Allen TJ, Story IH. Abdominal muscle recruitment during a range of voluntary exercises. Man Ther 2005;10:144-53.

25. Strohl KP, Mead J, Banzett RB, Loring SH, Kosch PC. Regional differences in abdominal muscle activity during various maneuvers in humans. J Appl Physiol Respir Environ Exerc Physiol 1981;51:1471-6.

26. De Troyer A, Estenne M, Ninane V, Van Gansbeke D, Gorini M. Transversus abdominis muscle function in humans. J Appl Physiol (1985) 1990;68:1010-6.

27. Teyhen DS, Rieger JL, Westrick RB, Miller AC, Molloy JM, Childs JD. Changes in deep abdominal muscle thickness during common trunk-strengthening exercises using ultrasound imaging. J Orthop Sports Phys Ther 2008;38:596-605.

28. Bohannon RW, Cassidy D, Walsh S. Trunk muscle strength is impaired multidirectionally after stroke.
Clin Rehabil 1995;9:47-51.

29. Tanaka S, Hachisuka K, Ogata H. Trunk rotatory muscle performance in post-stroke hemiplegic patients. Am J Phys Med Rehabil 1997;76:366-9.

30. Kuypers HG, Brinkman J. Precentral projections to different parts of the spinal intermediate zone in therhesus monkey. Brain Res 1970;24:29-48.

31. Carr LJ, Harrison LM, Stephens JA. Evidence for bilateral innervation of certain homologous motoneurone pools in man. J Physiol 1994;475:217-27.

32. Muller F, Kunesch E, Binkofski F, Freund HJ. Residual sensorimotor functions in a patient after right-sided hemispherectomy. Neuropsychologia 1991;29:125-45.

33. Hides JA, Richardson CA, Jull GA. Magnetic resonance imaging and ultrasonography of the lumbar multifidus muscle. Comparison of two different modalities. Spine (Phila Pa 1976) 1995;20:54-8.

34. Gwowdon JH, Fink JS. Paralysis and movement disorders. In: Harrison TR, Wilson JD, Isselbacher KJ, editors. Harrison's principles of internal medicine. 12th ed. New York: McGraw-Hill; 1991. p. 157-69.

35. Verheyden G, Vereeck L, Truijen S, Troch M, Herregodts I, Lafosse $\mathrm{C}$, et al. Trunk performance after stroke and the relationship with balance, gait and functional ability. Clin Rehabil 2006;20:451-8.

36. Bohannon RW. Recovery and correlates of trunk muscle strength after stroke. Int J Rehabil Res 1995;18:1627. 